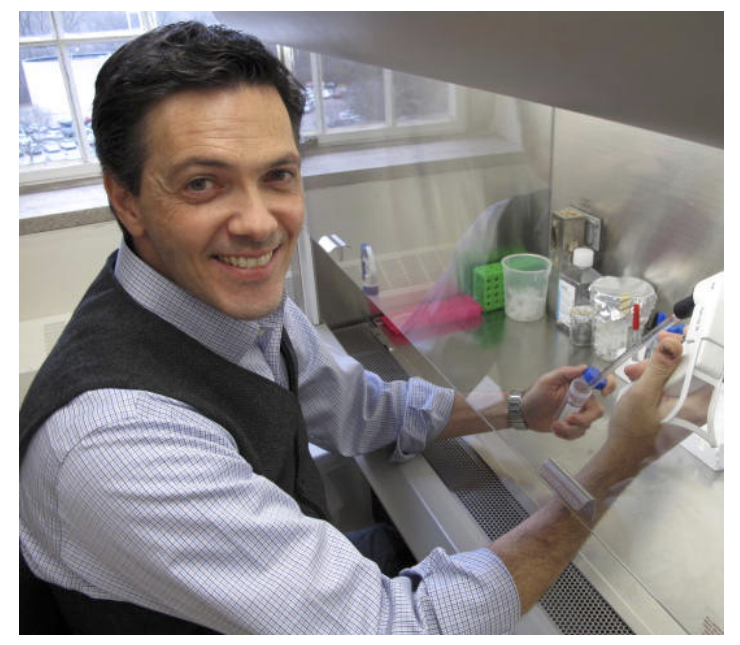

\section{Western Faculty Profile: Dr. Robert Cumming}

\author{
Amina Kassam ${ }^{1}$ \\ ${ }^{1}$ Faculty of Science, Western University, London, Canada \\ No conflicts of interest declared
}

\section{Tell us about yourself and your career path}

I started my undergraduate career at the University of Toronto, studying biology. It was not until about 1989 that I thought about performing research. A friend of mine suggested that I look into research opportunities at Sick Kids Hospital. I worked there for the summer in the field of pediatric neuro-oncology, which was my first exposure to the research field. I found it really interesting and it is ultimately what inspired me towards pursuing research.

After completing my undergrad, I was sure that I wanted to perform research, but I didn't know which field I wanted to specialize in. At that time, molecular medical genetics was the most popular field of research, so I applied and was accepted due to my previous research experience. I ended up returning to Sick Kids and working with Dr. Buchwald to study the gene which in mutated in a subset of Fanconi anemia patients. This research ended up being quite difficult and truly tested my resolve to stay in science.

After that, I returned to neuroscience and did my postdoctoral fellowship at the Salk Institute in San Diego. At the Salk, I worked on Alzheimer's Disease and a side project about metabolism. This research led to the discovery that brain cells become resistant to amyloid beta, a toxic peptide which is involved in Alzheimer's disease. Exposure to amyloid beta causes many cells to die off, but it also selects for cells that survive. The project identified that the cells that don't die when they were exposed to this peptide changed their metabolism which gave them a high affinity for glucose.

However, this field of research was not extremely appealing to me, so I left and switched to research on Huntington's disease. Along the way, an undergraduate student in my cell biology course brought up a paper that discussed the Warburg effect; a unique form of metabolism found in cancer cells. This paper was the first time I heard about this phenomenon. When I started to investigate it further, I found myself recalling the amyloid beta resistant cells I previously studied. On a whim, I got a hold of the cells from the Salk Institute and started to work with the student to see if the Warburg effect was present in the cells.
We quickly discovered that amyloid beta resistant cells indeed displayed the Warburg effect and produced the metabolite lactate, or lactic acid. Lactic acid can have both positive and negative effects on the body. We continued to build on what we found by looking into the brains of mice that were genetically engineered to build up the amyloid protein, which is present in patients with Alzheimer's. We hypothesized that the Warburg effect would be beneficial to brains with Alzheimer's, but were proven wrong.

When looking at the mice, it was found that the mice had levels of metabolism that were similar to Alzheimer patients but when correlated with memory, the mice did worse when the amyloid protein was present. We have identified that lactate production is good for a healthy aging brain, but seems to be bad in an Alzheimer's brain. Lactate metabolism doesn't seem to be working properly in people with Alzheimer's, causing this metabolite to build up and possibly making the disease worse. Most potential therapies for Alzheimer's have focused on getting rid of the amyloid beta peptide; with all clinical trials to date ending in failure. The abnormalities we detected in brain metabolism may be a strong contributing factor to the Alzheimer's, so one idea is to target the metabolism rather than the amyloid beta peptide.

\section{What Advice do you have for undergraduate students?}

Try not to be hyper-focused on marks; some of the best students in my lab did not have the highest marks. Marks don't predict everything, especially with respect to a student's capabilities in a lab. Good grades show that you are committed to learning and understanding the course content but don't necessarily predict how good you are at devising or running an experiment. Don't lose sight of the big picture and don't stress if you don't get the marks you wanted. The plans that you have now may not transpire and your career path may not end up as you originally envisioned but that is ok! 


\section{What qualities do you look for in a potential research assistant?}

Well, while I might first look at a student's marks, I would also be interested in what they have done beyond achieving good marks such as extracurricular activities or previous lab experience. I am sadly unable to take many students in my lab because of the limited available resources. A good research assistant candidate must prove to me that they are worthy of a position in my lab and are sincerely interested in my field of research. My suggestion is that you do some online research before you approach a professor; try to read the researcher's papers and show that you have tried to understand the purpose of their research. Work experience that may not directly relate to the field of research is still relevant as it shows that you are responsible and committed. Establish contact with the professor and show that you have made an attempt to understand their research. Be prepared!

\section{As a professor, what are the most rewarding and most challenging parts of teaching?}

I would say the most rewarding part of teaching is getting students enthused about the information and engaged about what they are learning. The challenging part is the process of getting them involved and enthusiastic about the course material! Coming up with new and innovative ways to deliver the course material can also be a little challenging at times, as I usually teach the same courses every year.

I also find it hard at times to simplify my second-year courses so that the students understand what I am teaching as it can be easy to overcomplicate concepts because many are so intricate. Students continually complain that I talk too fast, but I think that is because they try to transcribe everything that I say. A better way to take notes in my class would be to paraphrase and pull out the key points that I am trying to convey.

Technology is very enabling and it can become easy for students to spend a disproportionate amount of time re-listening to lectures and think everything is important. Technology is also enabling for us as professors, as we can compress all the information within a PowerPoint presentation. I think it is also important to have a dialogue with students and be able to discuss concepts and ideas with them, as this engages different parts of the brain and allows students to actively think - instead of passively transcribing while they are hearing.

\section{To Learn more on Dr. Cumming's lab and research, please visit his website:}

http://www.thecumminglab.com/ 